\title{
Age-related decrease in the overall extent of perikaryal projections in rabbit spinal ganglion neurons
}

\author{
E. Pannese*, P. Sartori, C. Martinelli, M. Ledda \\ Institute of Histology, Embryology and Neurocytology, University of Milan, via Mangiagalli 14, I-20133 Milan, Italy
}

Received 11 May 1998; received in revised form 9 July 1998; accepted 17 July 1998

\begin{abstract}
The overall extent of the perikaryal projections of sensory neurons from spinal ganglia of young adult and aged rabbits was estimated by a stereological method using the electron microscope. The extent of perikaryal projections was significantly smaller in the aged animals. This age-related decrease did not seem to depend on factors intrinsic to the neuron, but on the absence of a satellite cell covering over extensive portions of the nerve cell body surface. This decrease may influence the organization of the subplasmalemmal cytoskeleton, metabolic exchange between the nerve cell body and its environment and perhaps also neuronal metabolism. (c) 1998 Elsevier Science Ireland Ltd. All rights reserved
\end{abstract}

Keywords: Dorsal root ganglia; Sensory neurons; Aging; Perikaryal projections; Peripheral neuroglia; Oryctolagus cuniculus

The cell bodies of spinal ganglion neurons display numerous slender projections, which considerably increase the surface area available for exchange of metabolites (see $[8,9]$ for review). Since modifications in the overall extent of these projections may influence metabolic processes of the neuron or exchanges between the cell body and its environment, we have continued our studies on age-related structural changes in spinal ganglia by addressing the question as to whether this extent changes with age. As far as we are aware, no studies have been published on this problem.

Rabbits (Oryctolagus cuniculus) aged 12 months (two animals, one male and one female, $3.4-3.5 \mathrm{~kg}$ body weight) and 79-96 months (two animals, one male and one female, $4.0-4.2 \mathrm{~kg}$ body weight) were used. The dates of birth of these animals are well documented; all had been raised by a specialist rabbit breeder with particular attention to hygiene and regular veterinary inspections. Since the life span of the normal healthy Oryctolagus is 60-72 months [5] or 84-96 months [13], the 12-month-old rabbits we studied were young adults and the 79-96-month-old animals were aged rabbits. Furthermore, the end of fertility is usually considered to mark the onset of senescence and female rabbits are

\footnotetext{
* Corresponding author.Tel.: +39 02 70600962; fax: +39 02 70635928; e-mail: pannese@imiucca.csi.unimi.it
}

not normally fertile after 60 months, so that the 79-96month-old animals are to be considered aged also from this point of view.

The animals were perfused transcardially with a solution containing $2 \%$ formaldehyde and $2 \%$ glutaraldehyde in 0.1 $\mathrm{M}$ sodium cacodylate buffer ( $\mathrm{pH}$ 7.3) under deep anaesthesia with Nembutal $(80 \mathrm{mg} / \mathrm{kg})$. After fixation for about $3 \mathrm{~h}$, the thoracic spinal ganglia were removed, washed in cacodylate buffer $(0.2 \mathrm{M}, \mathrm{pH} 7.3)$ for $2 \mathrm{~h}$ and then postfixed on ice for $1.5 \mathrm{~h}$ in $2 \% \mathrm{OsO}_{4}$, buffered with $0.1 \mathrm{M}$ sodium cacodylate. The specimens were washed in distilled water, stained with $2 \%$ aqueous uranyl acetate, dehydrated in alcohol and embedded in Epon-Araldite resin. Several semithin sections were prepared from each ganglion and stained with $0.5 \%$ toluidine blue in $1 \%$ sodium borate. They were then examined in the light microscope to check the quality of fixation. Only the best preserved ganglia were used to study the extent of the perikaryal projections. Since even during optimum fixation, dehydration and embedding, there is some degree of cellular swelling or shrinkage, a basic assumption in our comparison of the perikaryal projections in young adult and old rabbits was that any artifactual volume changes were similar in both age groups. This assumption seems justified by the observation that in all the ganglia used for the present study the space between 
the nerve cell body and the enveloping satellite cell sheath was of fairly uniform width. Furthermore, neither empty areas nor clumping were observed in the connective tissue space surrounding the unit consisting of the nerve cell body and its enveloping satellite cell sheath. Overall, 40 ganglia (10 for each animal) were used for this study.

Although spinal ganglion neurons do not show preferred orientations and as a rule perikaryal projections are present over the entire surface of the neuron [7], the study was carried out on isotropic uniform random (IUR) sections obtained following the orientator procedure [6]. For each ganglion a single IUR thin section (about $0.25 \times 0.20 \mathrm{~mm}$ ) was photographed under the electron microscope. Each section was photographed in its entirety at a magnification of $\times 2500$ and the negatives printed to a final magnification of $\times 10000$. A montage of $60-70$ prints was necessary to reconstruct each section. A sheet of cardboard containing uniform-sized $(10 \times 5 \mathrm{~cm})$, systematically arranged windows was placed over the photomontage of each section. The outlines of the nerve cell bodies found within each window were traced with ink, cutting across the bases of the perikaryal projections. From now on, these outlines will be referred to as smoothed outlines. Next a transparent sheet containing a series of parallel test lines was placed over each window. The number of intersection points between the perikaryal plasma membranes within each window and the test lines $\left(I^{\prime}\right)$ were counted, as also were the number of intersection points between the traces of the smoothed outlines of the perikarya and the test lines $\left(I^{\prime \prime}\right)$. The ratio $F$ between $I^{\prime}$ and $I^{\prime \prime}$ gives an indication of the extension of the perikaryal projections being studied.

For each rabbit the mean value of $F$ and SD were calculated. The values obtained for the rabbits in each age group were then compared to establish whether they differed significantly. Finally, the data for the young adult rabbits were compared with the data for the aged animals. The statistical comparisons employed the two-tailed Student's $t$-test (differences with $P<0.05$ were considered significant) and for each value the $95 \%$ confidence limits were calculated. All data analyses were carried out using a statistical graphics program (Statgraphics) on a Compaq 386/s computer.
A survey of sections under the electron microscope did not reveal differences in the structure of nerve cell bodies and satellite cells between old and young adult rabbits. The quantitative data for each animal are shown in Table 1. The ratio $F$, which gives an indication of the extension of the perikaryal projections, did not differ between the two young adults or between the two old rabbits. The comparison between the two age groups (Table 1) showed that the ratio $F$ was significantly lower $(P<0.05)$ in the old rabbits than young adults. These data indicate that the overall extent of the perikaryal projections of spinal ganglion neurons is significantly lower in the aged rabbits.

In considering factors that may cause the decrease in the overall extent of perikaryal projections in the old rabbits, it is important to bear in mind the following. (a) In aged rabbits, unlike in young adults, the perisomatic satellite cell sheaths exhibit extensive gaps which leave the nerve cell body surface directly exposed to the extracellular matrix [10]. (b) Perikaryal projections are absent at the level of these gaps, but are present and normally developed in the surface domains covered by satellite cells [11]. These findings suggest that the decrease in the overall extent of perikaryal projections in old rabbits depends mainly on factors extrinsic to the neuron. Possibly the absence of a satellite cell covering along extensive areas of the nerve cell body surface is responsible for the lack of projections in these areas, with consequent decrease in the overall extent of perikaryal projections.

This decrease implies changes in the shape of the plasma membrane of the perikaryon. Observations on other cell types have shown that changes in the shape of the plasma membrane can influence the subplasmalemmal cytoskeleton $[1,3]$. Presumably, such changes also occur in the spinal ganglion neurons of the old rabbits. In support of this we draw attention to our finding that a dense undercoating is present beneath portions of the nerve cell body plasma membrane lacking perikaryal projections, but is absent elsewhere [10]. This undercoating, whose major constituents are microfilaments, seems to represent a reaction of the neuronal cytoskeleton to loss of the satellite cell covering. The undercoating appears similar to that situated beneath

Table 1

Quantitative results

\begin{tabular}{|c|c|c|c|c|c|}
\hline \multirow[t]{2}{*}{ Rabbit } & \multirow{2}{*}{$\begin{array}{l}\text { Age } \\
\text { (months) }\end{array}$} & \multirow{2}{*}{$\begin{array}{l}\text { Total number of } \\
\text { sections examined }\end{array}$} & \multicolumn{2}{|c|}{ Total number of intersection points with } & \multirow{2}{*}{$\begin{array}{l}\text { Mean ratio }( \pm \mathrm{SD}) \\
\text { between } I^{\prime} \text { and } I^{\prime \prime}(F)\end{array}$} \\
\hline & & & $\begin{array}{l}\text { plasma membranes of } \\
\text { the nerve cell bodies }\left(I^{\prime}\right)\end{array}$ & $\begin{array}{l}\text { smoothed outlines of } \\
\text { the nerve cell bodies }\left(I^{\prime \prime}\right)\end{array}$ & \\
\hline \multicolumn{6}{|c|}{ Values for each rabbit } \\
\hline 1 & 12 & 10 & 10258 & 5090 & $2.00 \pm 0.36$ \\
\hline 2 & 12 & 10 & 12593 & 6485 & $2.00 \pm 0.46$ \\
\hline 3 & 79 & 10 & 10567 & 6083 & $1.71 \pm 0.37$ \\
\hline 4 & 96 & 10 & 11724 & 6627 & $1.77 \pm 0.17$ \\
\hline \multicolumn{6}{|c|}{ Values for each age group } \\
\hline Young adult & & 20 & 22851 & 11575 & $2.00 \pm 0.42$ \\
\hline Old & & 20 & 22291 & 12710 & $1.72 \pm 0.34$ \\
\hline
\end{tabular}


the axolemma at the nodes of Ranvier, which has been suggested to be involved in anchoring plasma membrane particles [4]. If the layer of dense material observed in the present study plays a similar role, it is possible that the properties of the portions of the plasma membrane covered by satellite cells differ from those of the portions not covered.

However, little information is available to indicate which properties of the neuronal plasma membrane are modified in aged rabbits. In particular, it is not known whether excitability is modified. Even if this were the case, the change would only affect limited portions of the nerve cell body plasma membrane and this would have no significant influence on impulse propagation, since the cell body of these neurons is not in the propagation path. In these neurons the impulse propagates directly from the peripheral to the central axonal branch to reach the spinal cord; for this reason it is generally held that the nerve cell body is of little importance in their electrical activity.

Finally, it is likely that the reduction in the overall extent of perikaryal projections will influence the metabolic activity of the spinal ganglion neurons. In fact, this reduction changes the shape and reduces the extent of the plasma membrane of the cell body of these neurons. In other cell types it has been reported that changes in the shape of the plasma membrane can influence basic metabolic processes such as protein synthesis [2]. Moreover, a reduction in surface area would probably lead to a decrease in metabolic exchange between the neuron and its environment, which in turn may have negative consequences for neuronal metabolism. In this regard, note that the rate of protein synthesis declines in rat spinal ganglion neurons with age [12].

The authors wish to thank Mr. F. Redaelli for photographic assistance.

[1] Amato, P.A., Unanue, E.R. and Taylor, D.L., Distribution of actin in spreading macrophages: a comparative study on living and fixed cells, J. Cell Biol., 96 (1983) 750-761.

[2] Ben-Ze'ev, A., Farmer, S.R. and Penman, S., Protein synthesis requires cell-surface contact while nuclear events respond to cell shape in anchorage-dependent fibroblasts, Cell, 21 (1980) 365-372.

[3] Boyles, J. and Bainton, D.F., Changing patterns of plasma membrane-associated filaments during the initial phases of polymorphonuclear leukocyte adherence, J. Cell Biol., 82 (1979) 347-368.

[4] Bray, G.M., Rasminsky, M. and Aguayo, A.J., Interactions between axons and their sheath cells, Annu. Rev. Neurosci., 4 (1981) 127-162.

[5] Harkness, J.E. and Wagner, J.E., The Biology and Medicine of Rabbits and Rodents, 2nd edition, Lea and Febiger, Philadelphia, 1983.

[6] Mattfeldt, T., Mall, G., Gharehbaghi, H. and Möller, P., Estimation of surface area and length with the orientator, J. Microsc., 159 (1990) 301-317.

[7] Pannese, E., Neurocytology. Fine Structure of Neurons, Nerve Processes and Neuroglial Cells, Georg Thieme Verlag, Stuttgart, 1994.

[8] Pannese, E., Ledda, M., Conte, V. and Procacci, P., The perikaryal projections of rabbit spinal ganglion neurons. A comparison of thin section reconstructions and scanning microscopy views, Anat. Embryol., 181 (1990) 427-432.

[9] Pannese, E., Ledda, M., Conte, V., Procacci, P. and Matsuda, S., Scanning electron-microscope observations of the perikaryal projections of rabbit spinal ganglion neurons after enzymatic removal of connective tissue and satellite cells, Cell Tissue Res., 260 (1990) 167-173.

[10] Pannese, E., Procacci, P., Ledda, M. and Conte, V., Agerelated reduction of the satellite cell sheath around spinal ganglion neurons in the rabbit, J. Neurocytol., 25 (1996) 137146.

[11] Pannese, E., Procacci, P., Berti, E. and Ledda, M., The perikaryal surface of spinal ganglion neurons: differences between domains in contact with satellite cells and in contact with the extracellular matrix, Anat. Embryol., (1998) in press.

[12] van den Bosch de Aguilar, Ph. and Vanneste, J., Ageing of the spinal ganglion neurons in the rat: a radioautographic study following injection of $\left[{ }^{3} \mathrm{H}\right]$ lysine, Neurosci. Lett., 18 (1980) 225-230.

[13] Weisbroth, S.H., Flatt, R.E. and Kraus, A.L., The Biology of the Laboratory Rabbit, Academic Press, New York, 1974. 